\title{
Physicochemical Properties of Sn-Zn and SAC + Bi Alloys
}

\author{
TOMASZ GANCARZ, ${ }^{1,3}$ JANUSZ PSTRUŚ, ${ }^{1}$ WłADYSłAW GALIOR,${ }^{1}$ \\ and HANI HENEIN ${ }^{2}$
}

\begin{abstract}
1.-Institute of Metallurgy and Materials Science, Polish Academy of Sciences, Krakow, Poland. 2.-Department of Chemical and Materials Engineering, University of Alberta, Edmonton, AB, Canada. 3.—e-mail: nmgancar@imim-pan.krakow.pl
\end{abstract}

Applying the discharge crucible (DC) method, the viscosity, density, and surface tension were determined for $\mathrm{Sn}-9 \mathrm{Zn}$ and $\mathrm{Sn}-2.92 \mathrm{Ag}-0.4 \mathrm{Cu}-3.07 \mathrm{Bi}$ $(\mathrm{SAC}+\mathrm{Bi})$ alloys. For comparison, the dilatometric, maximum bubble pressure, and capillary flow methods were used for measurements of these same physicochemical properties for the Sn-2.92Ag-0.4Cu-3.07Bi $(\mathrm{SAC}+\mathrm{Bi})$ alloy. The measurements were performed for $\mathrm{Sn}-9 \mathrm{Zn}$ and $\mathrm{SAC}+\mathrm{Bi}$ alloys in the temperature range from $513 \mathrm{~K}$ to $723 \mathrm{~K}$ and $530 \mathrm{~K}$ to $1180 \mathrm{~K}$, respectively. The experimental data obtained show that addition of Bi to SAC increases the density and decreases the surface tension and viscosity in comparison with SAC solder. Additionally it was found that the properties studied by different methods (maximum bubble pressure, dilatometric, capillary flow, and discharge crucible) were almost identical.

Key words: Sn-Zn, SAC, density, surface tension, viscosity, physicochemical properties

\section{INTRODUCTION}

Over the past 20 years, researchers have invested a lot of effort in identifying substitutes for lead solders, as they are harmful to the environment. This trend was reinforced in Europe by the EU RoHS and WEEE directives. Based on the analysis of many binary and ternary systems, two groups of alloys are considered as potential replacements for lead solders. The first group are alloys based on the $\mathrm{Sn}-\mathrm{Ag}-\mathrm{Cu}$ system (SAC) with addition of different metals. ${ }^{1-6} \mathrm{Sn}-\mathrm{Zn}$ alloys with additions such as $\mathrm{Cu}, \mathrm{Ag}, \mathrm{In}, \mathrm{Sb}$, and $\mathrm{Bi}^{7-13}$ form the second group. Studies of the mechanical and technological properties (wettability, wear, etc.) conducted for SAC alloy by Zhao et al. ${ }^{14}$ and Kim and Jung ${ }^{15}$ showed that most investigated properties are similar to those of eutectic $\mathrm{Sn}-37 \mathrm{~Pb}$ solder.

In an earlier paper, ${ }^{16}$ measurements of surface tension, density, and viscosity were presented together with their temperature dependences for $\mathrm{SAC}$ and SAC + In. Complete description of the experimentally obtained mechanical properties,

(Received April 10, 2012; accepted October 24, 2012;

published online December 11, 2012) physicochemical and technological advances for $\mathrm{SAC}$ alloy with higher $\mathrm{Cu}$ content provides greater opportunities to use this alloy in industry. It was shown that addition of up to 3 at.\% $\mathrm{Cu}$ to the $\mathrm{Ag}-\mathrm{Sn}$ eutectic steadily increased the density and viscosity of the alloy but did not significantly change the surface tension or contact angle. Very good agreement was observed between experimental data for the same physical properties as determined by different measurement methods. Thermodynamic data of the Ag-Cu-Sn system were used by Moon et al. ${ }^{17}$ for calculation of the phase equilibria, and these data are used for the calculation of the melting temperature of various compositions as well as modeling of physicochemical properties.

Wide use of Sn-Zn-based solders is strongly limited by their oxidation. Addition of $\mathrm{Ag}, \mathrm{Bi}, \mathrm{In}, \mathrm{Cu}$ or $\mathrm{Sb}$ is explored in order to minimize oxidation of Sn-Zn near-eutectic solders. Moreover, as shown by Jiang et al., ${ }^{18}$ these additives increase the mechanical properties and decrease the surface tension, wetting angle, and electrical resistance of the binary alloy. Addition of $\mathrm{Bi}$ to eutectic $\mathrm{Sn}-\mathrm{Zn}$ alloy results in an improvement in the oxidation performance. $^{18}$ 
Study of the wettability of Sn-Zn alloys on $\mathrm{Cu}$ and $\mathrm{Ni}$ substrates by Zhang et al. ${ }^{7}$ showed that the contact angle (wettability) of Sn-9Zn alloy is about three times higher at $250^{\circ} \mathrm{C}$ compared with that of $\mathrm{Sn}-37 \mathrm{~Pb}$ alloy. As shown by Garcia et al., ${ }^{10}$ increase of the $\mathrm{Zn}$ content in the $\mathrm{Sn}-9 \mathrm{Zn}$ alloy does not improve its wettability. The advantage of $\mathrm{Bi}$ addition to the eutectic Sn-9Zn solder was shown by Suganuma and Kim, ${ }^{9}$ who found that small $\mathrm{Bi}$ additions to $\mathrm{Sn}-\mathrm{Zn}$ alloy decrease its melting temperature and increase its mechanical properties. Since addition of Bi to Sn-Zn eutectic alloy results in an improvement in mechanical properties, it is important to check the effect of such addition to SAC alloy on other properties. Comparative study of the influence of 3 mass $\% \mathrm{Bi}$ on the mechanical and technological properties of SAC and eutectic Sn-Zn solders was performed by Nakagawa et al. ${ }^{19}$ The results showed that, when soldering on $\mathrm{Pd}$ and $\mathrm{Au}$ substrates, SAC was characterized by higher mechanical properties than $\mathrm{Sn}-\mathrm{Zn}-3 \mathrm{Bi}$; results for $\mathrm{Ni}$ substrates were comparable. Additionally, modification of the $\mathrm{Sn}-\mathrm{Zn}$ eutectic by $\mathrm{Bi}$ addition led to increased mechanical properties of the soldered substrates in comparison with binary eutectic Sn$37 \mathrm{~Pb}$ in the case of all tested substrates. In the cited papers, the Young's modulus for the different alloys is given as $38.5 \mathrm{GPa}$ for SAC, $23.1 \mathrm{GPa}$ for Sn-Zn$3 \mathrm{Bi}$, and $25.6 \mathrm{GPa}$ for $\mathrm{Sn}-37 \mathrm{~Pb}$. It can be seen that the value of the modulus is similar for the Sn-Zn$3 \mathrm{Bi}$ and $\mathrm{Sn}-37 \mathrm{~Pb}$ alloys. Analysis of the effect of the $\mathrm{Bi}$ concentration in quaternary $\mathrm{Sn}-\mathrm{Ag}-\mathrm{Cu}-\mathrm{Bi}$ solders on various properties was conducted by Hwang ${ }^{20}$ and Takao et al. ${ }^{21}$ They suggested that the optimal concentration of $\mathrm{Bi}$ should be located in the range of 1 mass \% to 3.1 mass \%. In this study, the effect of bismuth addition to SAC and Sn-Zn eutectic alloys is reported. The density, surface tension, and viscosity were measured using the discharge crucible (DC) method. These physical property results are compared with earlier experimental data determined by other methods.

\section{EXPERIMENTAL PROCEDURES}

Binary and quaternary alloys were prepared by melting accurately weighed amounts of high-purity metals ( $\mathrm{Sn}, \mathrm{Zn}, \mathrm{Cu}, \mathrm{Bi} ; 99.999 \%$ ) in a glovebox under a protective atmosphere of high-purity argon, with water vapor, nitrogen, and oxygen concentrations lower than $1 \mathrm{ppm}$ to avoid oxidation of the liquid alloys. The Sn-2.92Ag-0.4Cu-3.07Bi (wt.\%) solders (further referred to as $\mathrm{SAC}+\mathrm{Bi}$ ) were melted in a graphite crucible and after casting used for measurements of surface tension by the maximum bubble pressure (MBP) method, density by dilatometer (Dl) technique ${ }^{22}$ viscosity by capillary flow (CF) method, ${ }^{39}$ and density, viscosity, and surface tension by the DC method, as described in detail elsewhere. ${ }^{23,24}$ In this study, the Sn-9Zn alloy sample was investigated by the DC method only. This method is based on the relation describing the volumetric flow rate of liquid, $Q$, exiting a crucible through an orifice and is mathematically described using the Froude (Fr) and Bond (Bo) numbers as follows:

$$
\begin{gathered}
\mathrm{Fr}+1 / \mathrm{Bo}=1, \\
\mathrm{Bo}=\frac{\rho g r_{0} h}{\sigma}, \\
\mathrm{Fr}=\frac{\left(\frac{Q}{\pi r_{0}^{2} C_{\mathrm{d}}}\right)^{2}}{2 g h} .
\end{gathered}
$$

If the relationship between $C_{\mathrm{d}}$ and Re (the Reynolds number) is described using a cubic polynomial, then the height of the melt in the crucible can be written as

$$
\begin{aligned}
h= & \frac{1}{2 g}\left(\frac{Q}{\left(a_{4}\left(\frac{2 \rho Q}{\pi r_{0} \eta}\right)^{3}+a_{3}\left(\frac{2 \rho Q}{\pi r_{0} \eta}\right)^{2}+a_{2}\left(\frac{2 \rho Q}{\pi r_{0} \eta}\right)+a_{1}\right) \pi r_{0}^{2}}\right) \\
& +\frac{\sigma}{\rho g r_{0}},
\end{aligned}
$$

where $\rho$ is the density of the liquid $\left(\mathrm{kg} / \mathrm{m}^{3}\right), g$ is the gravitational acceleration $\left(\mathrm{m} / \mathrm{s}^{2}\right), r_{0}$ is the radius of the orifice at the bottom of the crucible $(\mathrm{m}), \sigma$ is the surface tension $(\mathrm{mN} / \mathrm{m}), Q$ is the free flow $\left(\mathrm{m}^{3} / \mathrm{s}\right), C_{\mathrm{d}}$ is the discharge coefficient determined for a given crucible based on the free flow of liquids of known density, viscosity, and surface tension, and $a_{1}, a_{2}$, and $a_{3}$ are constants in the polynomial describing $C_{\mathrm{d}}$ versus Re.

The cumulative weight of liquid, $C_{\mathrm{m}}$, i.e., the mass of liquid that flows freely from the crucible in time $t$, is measured in the course of an experiment, being commonly described by a polynomial of order 2 to 4 (Eq. 5):

$$
C_{\mathrm{m}}=\sum_{i=1}^{4} C_{i} t^{i-1}
$$

and used for the calculation of free flow $Q$ according to Eq. 6:

$$
Q=\frac{3 C_{4} t^{2}+C_{3} t+C_{2}}{\rho} .
$$

Based on the Hooke-Jeeves method, ${ }^{25}$ numerical solutions of Eq. 4 for each alloy were conducted, and the density, surface tension, and viscosity were calculated. $^{23,24}$ The crucibles used in these experiments have the same dimensions as those used in our previous work. ${ }^{23}$

The study was conducted for Sn-9Zn and SAC + $\mathrm{Bi}$ in the temperature range of $513 \mathrm{~K}$ to $723 \mathrm{~K}$ and $530 \mathrm{~K}$ to $1180 \mathrm{~K}$, respectively. They were also studied by dilatometric (density), MBP (surface tension), and CF (viscosity) methods ${ }^{22,23}$ in a 
Table I. Linear and Arrhenius dependences for Sn-15Zn and SAC + 3.07Bi for density, surface tension, and viscosity with errors, and parameters determined for temperature of $623 \mathrm{~K}$

\begin{tabular}{|c|c|c|c|c|c|c|}
\hline \multirow[b]{2}{*}{ Alloy } & \multicolumn{2}{|c|}{$\rho=A+B \times T$} & \multirow[b]{2}{*}{$\rho(623 \mathrm{~K})\left(\mathrm{g} \mathrm{cm}^{-3}\right)$} & \multirow[b]{2}{*}{$\partial \rho\left(\mathrm{g} \mathrm{cm}^{-3}\right)$} & \multirow[b]{2}{*}{$\partial \boldsymbol{A}$} & \multirow[b]{2}{*}{$\partial B$} \\
\hline & $\boldsymbol{A}$ & $\boldsymbol{B}$ & & & & \\
\hline $\mathrm{Sn}-9 \mathrm{Zn}$ & 7.348 & -0.000758 & 6.875 & \pm 0.027 & \pm 0.011 & \pm 0.00002 \\
\hline \multirow[t]{3}{*}{$\mathrm{SnAgCu}-3.07 \mathrm{Bi}$} & 7.509 & -0.000660 & 7.098 & \pm 0.106 & \pm 0.006 & \pm 0.00001 \\
\hline & \multicolumn{2}{|c|}{$\sigma=A+B \times T$} & & & & \\
\hline & $\boldsymbol{A}$ & $\boldsymbol{B}$ & $\sigma(623 \mathrm{~K})\left(\mathrm{mN} \mathrm{m}^{-1}\right)$ & $\partial \sigma\left(\mathbf{m N ~ m} \mathbf{m}^{-1}\right)$ & $\partial A$ & $\partial B$ \\
\hline $\mathrm{Sn}-9 \mathrm{Zn}$ & 615.7 & -0.953 & 556.3 & \pm 5 & \pm 1.7 & \pm 0.003 \\
\hline \multirow[t]{3}{*}{$\mathrm{SnAgCu}-3.07 \mathrm{Bi}$} & 574.0 & -0.0833 & 522.1 & \pm 3.2 & \pm 1.6 & \pm 0.003 \\
\hline & \multicolumn{2}{|c|}{$\eta=A \times \mathbf{e}^{E / R T}$} & & & & \\
\hline & $\boldsymbol{A}$ & $\boldsymbol{E}$ & $\eta(623 \mathrm{~K})(\mathbf{m P a} \mathbf{s})$ & $\partial \eta(\mathbf{m P a} \mathbf{s})$ & $\partial \boldsymbol{A}$ & $\partial E$ \\
\hline $\mathrm{Sn}-9 \mathrm{Zn}$ & 0.355 & 7855.3 & 1.617 & \pm 0.013 & \pm 0.019 & \pm 129.2 \\
\hline SnAgCu-3.07Bi & 0.383 & 6806.0 & 1.623 & \pm 0.011 & \pm 0.018 & \pm 96.2 \\
\hline
\end{tabular}

protective atmosphere of high-purity Ar and in the same laboratory as these investigations.

The temperature dependences of density and surface tension were described by a linear relationship and the viscosity by an Arrhenius equation; they are presented in Table I along with estimated errors of the equation parameters and values calculated at the temperature of $623 \mathrm{~K}$.

\section{RESULTS AND DISCUSSION}

The experimental results for the studied alloys together with literature data are presented in Figs. 1-7. Table I presents the regression equations describing the temperature dependences of the measured quantities.

The experimental results for the density and surface tension of Sn-9Zn alloy obtained using the DC method are presented in Figs. 1 and 2, respectively, along with literature data. ${ }^{2,23}$ The literature data were obtained using dilatometric and MBP methods for density and surface tension, respectively. The density results of this study obtained by the DC method are almost the same as those measured by Moser et al. ${ }^{23}$ for 9.9 wt. $\%$, slightly higher than those of Pstruś et al. ${ }^{22}$ for $10 \mathrm{wt} . \% \mathrm{Zn}$, and slightly lower than those of Moser et al. ${ }^{23}$ for $7.1 \mathrm{wt} \% \mathrm{Zn}$. As seen from Fig. 1, the density of $\mathrm{Sn}-\mathrm{Zn}$ alloy decreases with increase in $\mathrm{Zn}$ content.

Addition of zinc has the opposite effect on the surface tension of Sn-Zn liquid alloys, as shown in Fig. 2. The plotted results were obtained by the DC (this study, Sn-9Zn) and MBP methods. ${ }^{22,23}$ As for the density, the experimental data for surface tension of the Sn-9Zn alloy from this study agree very well with those measured by Moser et al. ${ }^{22}$ and are

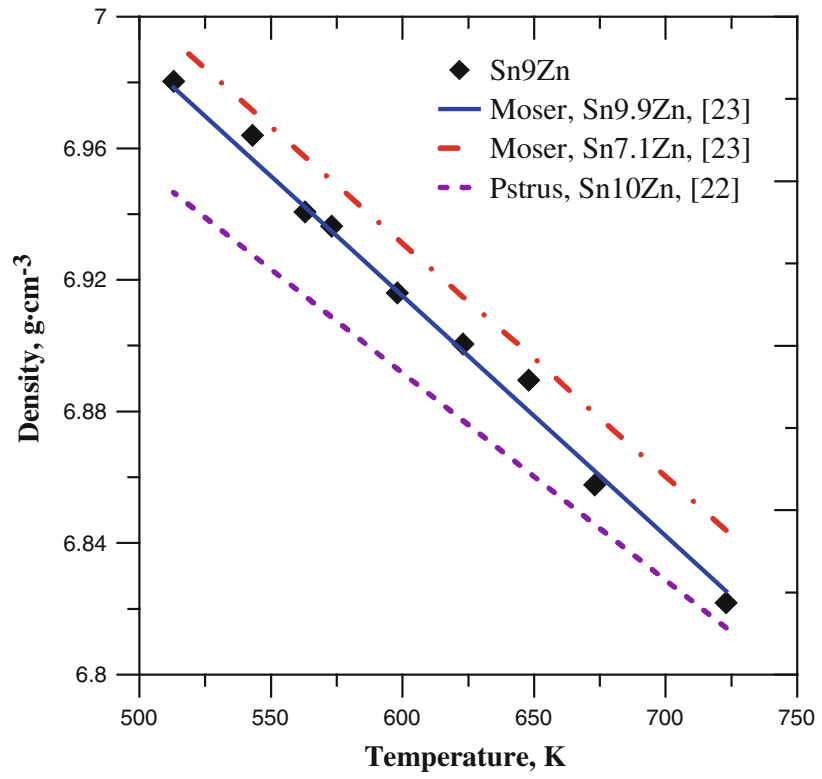

Fig. 1. Comparison of temperature dependence of density for Sn-9Zn alloy measured in this work by the DC method and those from the literature. ${ }^{22,23}$

lower than those obtained by Pstrus et al. ${ }^{22}$ for Sn-7.1Zn and higher than those for Sn-10Zn alloys.

Taking into consideration that the experimental error of the MBP method does not exceed $3 \%$ for the surface tension and $1.5 \%$ for the density measurements by dilatometric method, ${ }^{27}$ one can stay that the results from each of these different experimental methods are highly consistent with those obtained by the DC method.

The viscosity data for $\mathrm{Sn}-9 \mathrm{Zn}$ are shown in Fig. 3 along with literature data measured by different 


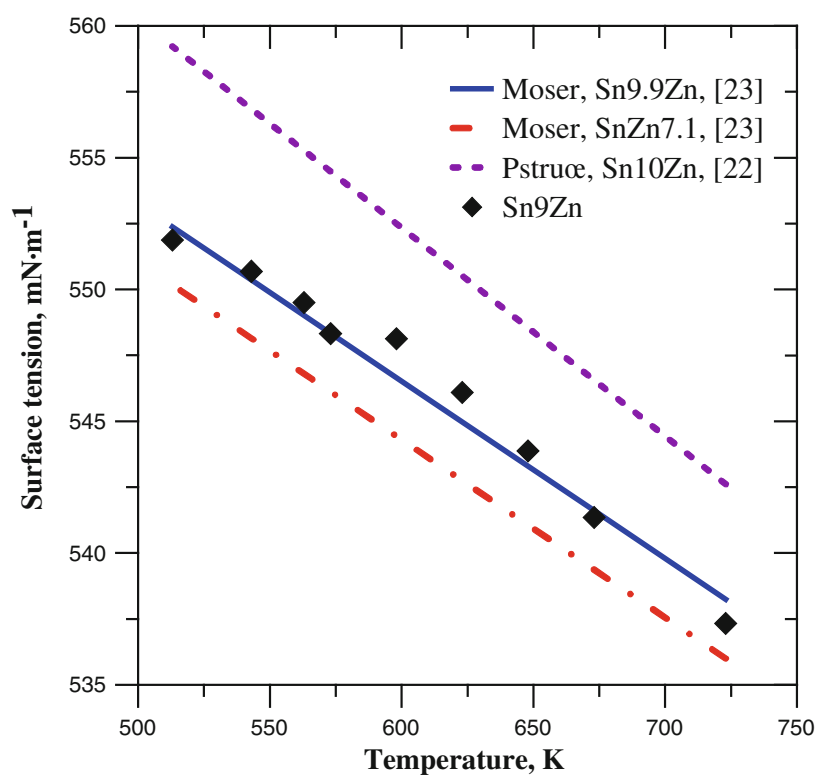

Fig. 2. Temperature dependences of surface tension for Sn-9Zn alloy obtained in this study by the DC method along with literature data. ${ }^{22,23}$

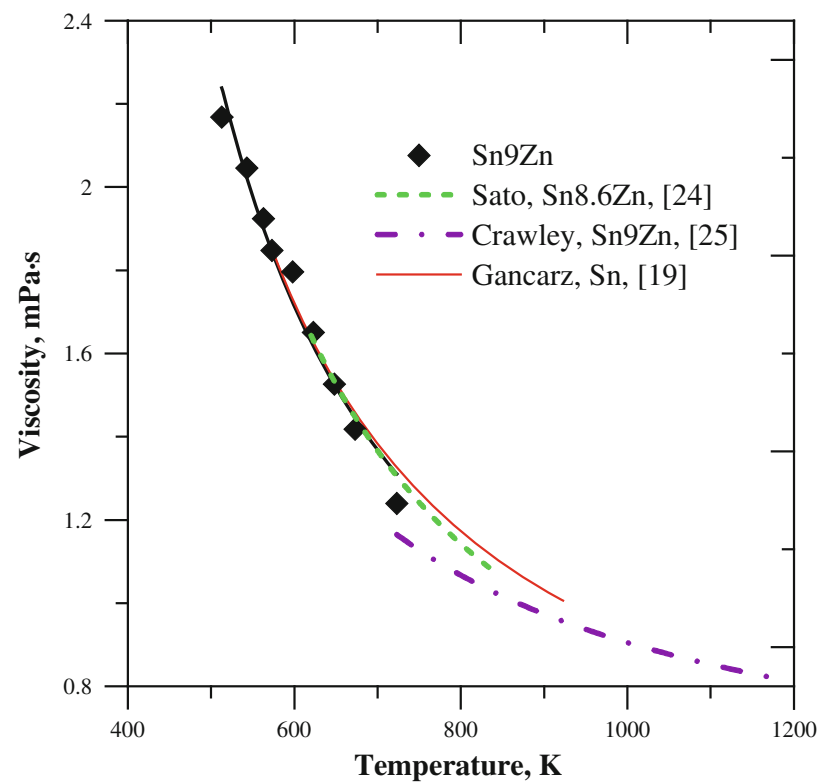

Fig. 3. Viscosity temperature dependence for Sn-9Zn alloy determined by authors of this work by the DC method together with literature data. ${ }^{19,24,25}$

experimental techniques: oscillatory, rotating, and free outflow from the DC method. Experimental values of viscosity for $\mathrm{Sn}-9 \mathrm{Zn}$ alloy correlate very well with literature data of Sato ${ }^{28}$ and Crawley ${ }^{29}$ and are comparable to those for Sn. ${ }^{19}$

The calculation of the density of Sn-9Zn and $\mathrm{SAC}+3.07 \mathrm{Bi}$ alloys using the rule of mixtures for $\mathrm{Sn}-9 \mathrm{Zn}$ and $\mathrm{SAC}+3.07 \mathrm{Bi}$ is based on the following relation:

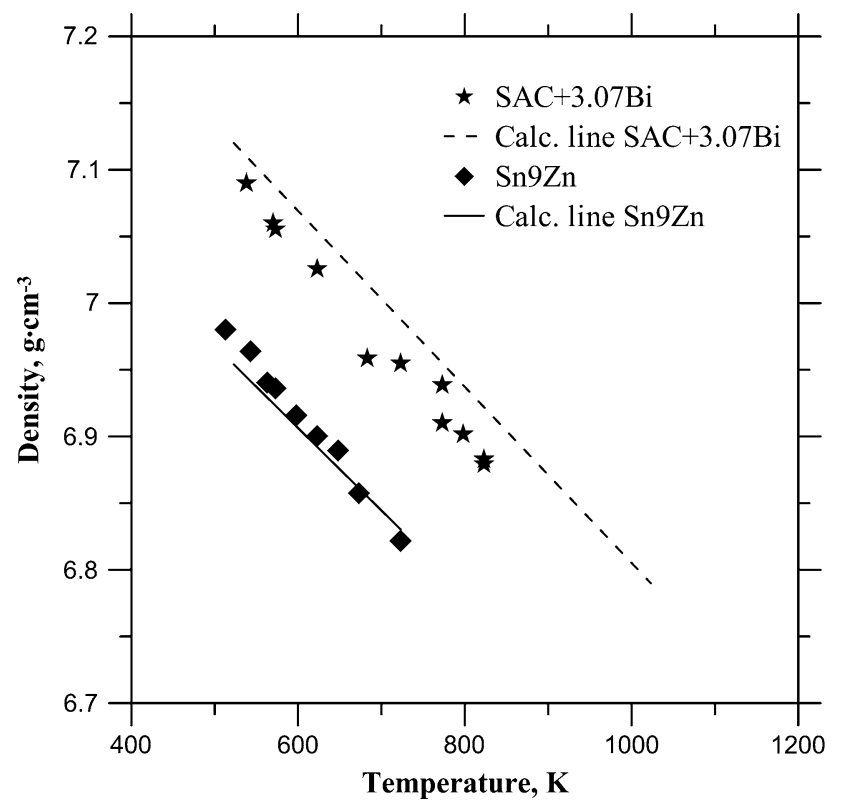

Fig. 4. Comparison of the density of Sn-9Zn and SAC-3.1Bi alloys by $\mathrm{DC}$ method with the calculated additive density of these alloys.

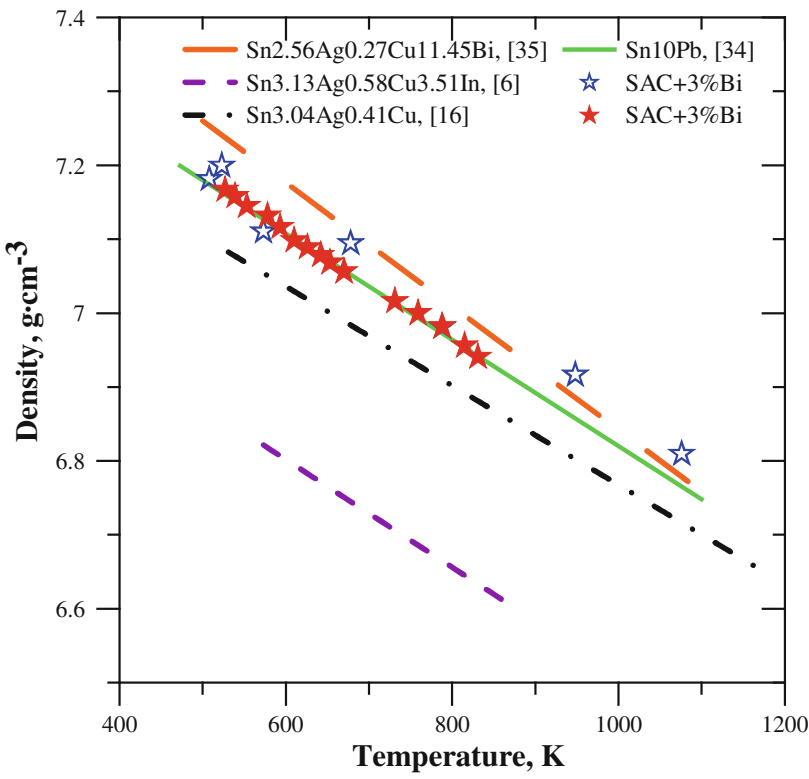

Fig. 5. Temperature dependence of density of $\mathrm{SAC}+3 \mathrm{Bi}$ alloys obtained by two measurement methods (DC, DI) in this study along with literature data. $6,16,27$

$$
\rho_{\text {calc }}=\sum_{1}^{n} X_{i} \rho_{i}
$$

where $\rho_{i}$ is the density of pure metal and $X_{i}$ is its mole fraction; the temperature dependence of density for pure metals, applied in Eq. 7, was taken from literature as follows: $\mathrm{Ag},{ }^{30} \mathrm{Bi},{ }^{31} \mathrm{Cu},{ }^{32} \mathrm{Sn},{ }^{23}$ Zn. ${ }^{33}$ 


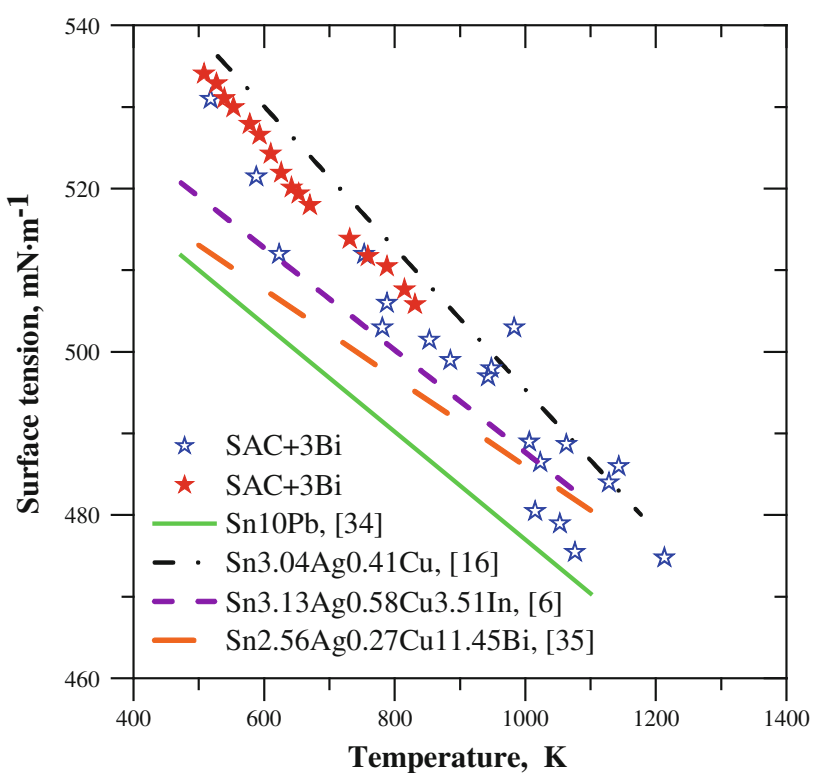

Fig. 6. Surface tension of $\mathrm{SAC}+3 \mathrm{Bi}$ alloys measured at different temperatures by two methods (DC, MBP) in this study along with literature data. ${ }^{6,16,27}$

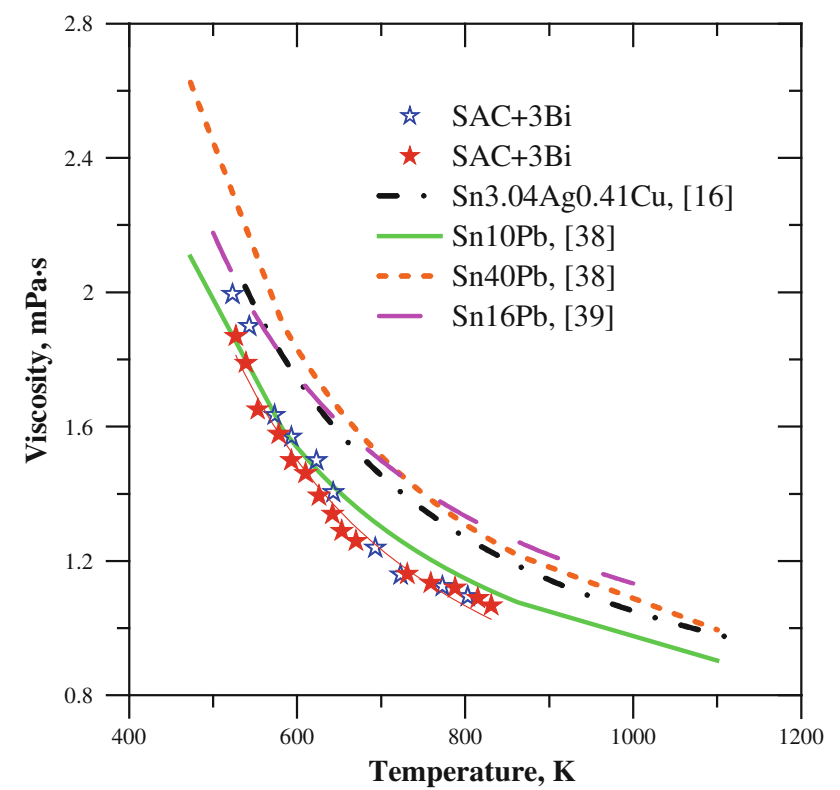

Fig. 7. Comparison of viscosity temperature dependences for SAC and $\mathrm{SAC}+\mathrm{Bi}$ liquid solders by two measurement methods (DC, CF) with $\mathrm{Pb}-\mathrm{Sn}$ solder viscosity.

A comparison between the calculated results based on Eq. 7 and the measured values for $\mathrm{SAC}+3.07 \mathrm{Bi}$ and Sn-9Zn is shown in Fig. 4. In the case of binary Sn-9Zn alloy, the calculated density is almost the same as that measured by the DC method, and in the case of the quaternary ( $\mathrm{SAC}+\mathrm{Bi}$ ) alloy the experimental data are slightly lower than the values calculated using Eq. 7. However, the calculated data are within the measurement error limits.
The density of $\mathrm{SAC}+3 \mathrm{Bi}$ alloy measured in this study is shown in Fig. 5, together with literature data. ${ }^{16,34,35}$ The experimental values obtained by the DC and Dl methods are almost identical and in very good agreement with literature values for $\mathrm{Sn}$ $10 \mathrm{~Pb}$ solder ${ }^{34}$ over the entire temperature range. The increase in density with an increase in Bi concentration in the SAC + Bi alloy was also observed in Ref. ${ }^{35}$, and the values measured in this study for $\mathrm{SAC}+3 \mathrm{Bi}$ alloy are slightly higher than those for $\mathrm{SAC}(\sim 2 \%){ }^{16}$

Addition of $\mathrm{Bi}$ to the $\mathrm{SAC}$ resulted in a small decrease of the surface tension in comparison with SAC, ${ }^{16}$ as shown in Fig. 6 . The values of surface tension of $\mathrm{SAC}+3 \mathrm{Bi}$ are lower compared with $\mathrm{Sn}-10 \mathrm{~Pb}$ by about $5 \%$ throughout the temperature range. The same effect of decreasing surface tension with increasing $\mathrm{Bi}$ concentration was observed by other authors. ${ }^{35}$ This effect can be explained by enrichment of $\mathrm{Bi}$ in the surface layer. Because bismuth has the lowest surface tension of the four metals of the alloys $\left(\sigma_{\mathrm{Bi}}<\sigma_{\mathrm{Sn}}<\sigma_{\mathrm{Ag}}<\sigma_{\mathrm{Cu}}\right),{ }^{36}$ the system seems to lower its energy by segregating the component with the lowest surface tension to the surface. ${ }^{37}$

In Fig. 7, the viscosity measurements of $\mathrm{SAC}+3 \mathrm{Bi}$ are compared with literature data and values measured by different methods. It can be seen that the viscosity values obtained by the DC and CM methods are almost identical. The viscosity values of the $\mathrm{SAC}+\mathrm{Bi}$ alloy show that $\mathrm{Bi}$ addition decreases this property of the SAC solder by about $10 \%$. It should also be pointed out that the viscosity of SAC + Bi alloy reported in this study and that of $\mathrm{SAC}^{16}$ are comparable to those for $\mathrm{Sn}-10 \mathrm{~Pb}$ solder, ${ }^{38}$ and $\mathrm{Sn}-16 \mathrm{~Pb},{ }^{39}$ and $\mathrm{Sn}-40 \mathrm{~Pb}$ solder, ${ }^{38}$ respectively.

\section{CONCLUSIONS}

Using DC, dilatometric, MBP, and CF methods, measurements of density, surface tension, and viscosity were performed for SAC-3.07Bi solder.

The values obtained for these physicochemical properties by two methods showed excellent agreement with each other, and the observed differences between the measured quantities were lower than $1 \%$. The results are also comparable to those in the literature.

Addition of Bi to SAC alloy results in an increase in the density and a decrease in the viscosity and the surface tension of the alloy in comparison with the base alloy. Similar trends are reported when Bi is added to $\mathrm{Sn}-\mathrm{Zn}$. The $\mathrm{SAC}+\mathrm{Bi}$ alloy studied here showed property values very similar to those of $\mathrm{Pb}$ Sn solder alloys over a large temperature range.

Furthermore, Hwang ${ }^{19}$ reported that a quaternary $\mathrm{Sn}-\mathrm{Ag}-\mathrm{Cu}-\mathrm{Bi}$ alloy with composition 93.3Sn$3.1 \mathrm{Ag}-0.5 \mathrm{Cu}-3.1 \mathrm{Bi}$, close to that studied in this work, offered the best balance between melting temperature, strength, plasticity, and fatigue life. 
Thus, this $\mathrm{SAC}+\mathrm{Bi}$ alloy shows promise as a new lead-free solder.

\section{ACKNOWLEDGEMENTS}

This work was financed by the Ministry of Science and Higher Education of Poland within Project No. 630/N Kanada/2009 "Using a new method for simultaneous measurement of surface tension, density and viscosity for use in soldering materials and new alloys for the automotive industry."

\section{OPEN ACCESS}

This article is distributed under the terms of the Creative Commons Attribution License which permits any use, distribution, and reproduction in any medium, provided the original author(s) and the source are credited.

\section{REFERENCES}

1. S. Kim, J. Lee, B. Jung, S. Lee, K. Kang, and K. Lim, Int. J. Thermophys. doi:10.1007/s10765-009-0599-x.

2. Multicore Ecosol TSC Product Information (MSL Ref: 733 9/ 99).

3. V. Solberg, Proceedings of NEPCON West 2000 Conference, Feb. 28-Mar. 2, 2000, Anaheim, CA (Source: Indium Corporation).

4. S.K. Kang, W.K. Choi, D.-Y. Shih, D.W. Henderson, T. Gosselin, A. Sarkhel, C. Goldsmith, and K.J. Puttlitz, IBM Research Report, RC22717 (W0302-019), February 5, 2003.

5. M.F. Arenas and V.L. Acoff, J. Electron. Mater. 33, 1452 (2004).

6. Z. Moser, P. Fima, K. Bukat, J. Sitek, J. Pstruś, W. Gạsior, M. Kościelski, and T. Gancarz, Solder. Surf. Mt. Technol. 23, 22 (2011).

7. L. Zhang, S. Xue, L. Gao, G. Zeng, Y. Chen, and S. Yu, J. Mater. Sci. Mater. Electron. 21, 1 (2010).

8. S. Kim, K. Kim, S. Kim, and K. Suganuma, J. Electron. Mater. 38, 266 (2009).

9. K. Suganuma and K. Kim, Sn-Zn low temperature solders. J. Mater. Sci.: Mater. Electron. 18, 121 (2007).

10. L. Garcia, W. Osorio, L. Peixoto, and A. Garcia, J. Electron. Mater. 38, 2405 (2009).

11. S. Yu, C. Liao, M. Hon, and M. Wang, J. Mater. Sci. 35, 4217 (2000).

12. C. Huang and K. Lin, Mater. Trans. 45, 588 (2004).

13. T. Takemoto and M. Miyazaki, Mater. Trans. 42, 745 (2001).

14. J. Zhao, Y. Mutoh, Y. Miyashita, and S.L. Mannan, J. Electron. Mater. 31, 879 (2002).
15. J.-W. Kim and S.-B. Jung, Mater. Sci. Eng. A 371, 267 (2004).

16. P. Fima, T. Gancarz, J. Pstrus, K. Bukat, and J. Sitek, Solder. Surf. Mt. Technol. 24, 71 (2012).

17. K.-W. Moon, W.J. Boettinger, U.R. Kattner, F.S. Biancaniello, and C.A. Handwerker, J. Electron. Mater. 29, 1122 (2000).

18. J. Jiang, J. Lee, K. Kim, and K. Suganuma, J. Alloys Compd. 462, 244 (2008).

19. Y. Nakagawa, Y. Aoki, and T. Nagai, Evaluating Joint Reliability of Sn-Zn Low-Temperature, Lead-Free Solder (Shanghai: Espec Environmental Test Technology Center Corp. Yokohama Branch). http://www.espec.co.jp/english/ tech-info/tech_info/tech-report_pdf_a08.html.

20. J.S. Hwang, Lead-Free Implementation and Production. A Manufacturing Guide (New York: McGraw-Hill, 2005).

21. H. Takao and H. Hasegawa, J. Electron. Mater. 30, 1060 (2001).

22. Z. Moser, W. Gasior, K. Bukat, J. Pstruś, and J. Sitek, Arch. Metal. Mater. 53, 1055 (2008).

23. T. Gancarz, Z. Moser, W. Gasior, J. Pstrus, and H. Henein, Int. J. Thermophys. 32, 1210 (2011).

24. S.J. Roach and H. Henein, Metall. Mater. Trans. B 36, 667 (2005).

25. M. Johnson, hooke.c: Nonlinear optimization using the algorithm of Hooke and Jeeves, http://www.netlib.org/opt/ hooke.c, 1994, based on A. F. Kaupe Jr, Algorithm 178, Direct Search, contain amendments Bell and Pike, CACM v.9, 684, September (1966) and the Tomlin and Smith, Remark on Algorithm 178, CACM v.12.

26. J. Pstruś, Z. Moser, W. Gąsior, and A. Dębski, Arch. Metal. Mater. 51, 335 (2006).

27. Z. Moser, W. Gạsior, J. Pstruś, I. Kaban, and W. Hoyer, Int. J. Thermophys. 30, 1811 (2009).

28. T. Sato and S. Munakata, Bull. Res. Inst. Miner. Dress. Metall. 11, 183 (1955).

29. A. Crawley and D. Kiff, Met. Trans. 3, 157 (1972).

30. E. Gebhardt and M. Becker, Z. Metallkde. 44, 379 (1953).

31. K. Okajima and H. Sakao, Trans. Jpn. Inst. Met. 23, 111(1982).

32. E. Gebhardt and G. Worwag, Z. Metallkde. 42, 358 (1951).

33. T. Gancarz, W. Gasior, and H. Henein, Int. J. Thermophys (Under review).

34. I. Kaban, S. Mhiaoui, W. Hoyer, and J.-G. Gasser, J. Phys. Condens. Matter 17, 7867 (2005).

35. Z. Moser, W. Gasior, K. Bukat, J. Pstrus, R. Kisiel, J. Sitek, K. Ishida, and I. Ohnuma, J. Phase Equilib. Differ. 27, 133 (2006).

36. P. Fima, Int. J. Mater. Res. (2012). doi:10.3139/146.110819.

37. I. Egry, Z. Metallkd. 92, 1 (2001).

38. Yu. Plevachuk, V. Sklyarchuk, W. Hoyer, and I. Kaban, J. Mater Sci., 160 (2006).

39. W. Gasior, Z. Moser, J. Pstrus, and M. Kucharski, Arch. Metall. Mater. 46, 23 (2001). 